\title{
Avanços e desafios do Programa de Volta para Casa como estratégia de desinstitucionalização: revisão integrativa
}

\author{
Advances and challenges of the Back Home Program as a \\ deinstitutionalization strategy: an integrative review
}

Helder de Pádua Lima (https://orcid.org/0000-0002-3795-6343) ${ }^{1}$

Debora Barbosa da Silva (https://orcid.org/0000-0002-6505-7580) ${ }^{1}$

Nathan Aratani (https://orcid.org/0000-0002-4602-7319) ${ }^{1}$

Guilherme Oliveira de Arruda (https://orcid.org/0000-0003-1690-4808) ${ }^{1}$

Soraia Geraldo Rozza Lopes (https://orcid.org/0000-0002-8938-2169) ${ }^{1}$

Priscielly Souza de Palhano (https://orcid.org/0000-0002-2944-1905) ${ }^{1}$

Kaely Virgínia de Oliveira Saraiva (https://orcid.org/0000-0002-3730-6535) ${ }^{1}$

Eysler Gonçalves Maia Brasil (https://orcid.org/0000-0002-4126-2256) ${ }^{2}$
${ }^{1}$ Universidade Federal de Mato Grosso do Sul. Avenida Márcio Lima Nantes s/n, Campus Universitário. 79400-000 Coxim MS Brasil.

padua_helder@hotmail.com

${ }^{2}$ Universidade da Integração Internacional da Lusofonia

Afro-brasileira. Redenção

CE Brasil.

\begin{abstract}
The aim of the current article is to identify scientific evidence about advances, possibilities, and challenges of using the Back Home Program (BHP) to deinstitutionalize former psychiatric hospitalization patients. This study is an integrative review based on the scientific literature available in the Virtual Health Library and the PubMed portal, as well as in the Cinahl, ScienceDirect, Web of Science, Scopus, and PsycINFO databases. The analysis of all nine selected studies was based on the interpretation of discursive practices observed in public domain materials. Results have shown that the investigated program is an undeniable social achievement and civilizing advance, and that it contributes to deinstitutionalization, as it helps to change beneficiaries' lives, with emphasis on their new consolidated place in society and on the dispensability of psychiatric hospitals. However, the program needs to overcome some challenges, such as access and equitable distribution in the national territory, professional training, and the involvement of individuals in the appropriation of benefits. It is crucial to emphasize the need to develop strategies to promote autonomy, citizenship, access to a broad mental health network of assistance and care resources, patients' return to family life, and insertion in the labor market.
\end{abstract}

Key words Mental health, Public policy, Deinstitutionalization
Resumo O objetivo deste artigo é identificar evidências científicas sobre os avanços, as possibilidades e os desafios do Programa de Volta para Casa para a desinstitucionalização de egressos de internações psiquiátricas. Trata-se de uma revisão integrativa realizada a partir da literatura científica encontrada na Biblioteca Virtual em Saúde, no portal PubMed, e nas bases de dados Cinahl, ScienceDirect, Web of Science, Scopus e PsycINFO. Fundamentou-se a análise das nove produções selecionadas na interpretação de práticas discursivas em materiais de domínio público. Os resultados evidenciaram que o programa representa inegável conquista social e avanço civilizatório; e contribui para a desinstitucionalização, à medida que proporciona mudanças na vida do beneficiário, com destaque para a ocupação concreta de outro lugar na sociedade e a prescindibilidade do hospital psiquiátrico. No entanto, apresenta desafios a serem superados quanto ao acesso e distribuição equitativa em território nacional, formação profissional e implicação do sujeito na apropriação do benefício. Ressalta-se a necessidade de estratégias de promoção da autonomia, cidadania, acesso a uma rede de saúde mental ampla de recursos assistenciais e de cuidado, retorno ao convivio familiar e inserção no mercado de trabalho.

Palavras-chave Saúde mental, Política pública, Desinstitucionalização 


\section{Introdução}

Desde seu surgimento, a Reforma Psiquiátrica Brasileira possibilitou o debate e a construção de novas estratégias que delinearam um outro lugar social para a loucura dentro da tradição cultural do país ${ }^{1}$. Trata-se de um movimento complexo que, para se constituir como política pública, organizou um conjunto de ações que extrapolam a criação de alternativas de desospitalização psiquiátrica, avançam no processo de desinstitucionalização e implicam na mobilização dos sujeitos envolvidos no sistema de ação institucional (pacientes, familiares, trabalhadores, gestores e outros agentes) e na transformação das relações de poder entre a instituição e as pessoas por ela assistidas ${ }^{2,3}$.

O Programa de Volta para Casa (PVC), juntamente com o Programa de Redução de Leitos Hospitalares de longa permanência e os Serviços Residenciais Terapêuticos (SRTs), consiste em uma estratégia para a desinstitucionalização e o resgate da cidadania de pessoas acometidas por transtornos mentais submetidas à privação de liberdade em instituições psiquiátricas, no contexto da Reforma Psiquiátrica Brasileira. O PVC foi regulamentado pela Lei Federal $n^{\circ} 10.708 / 2003$ como um auxílio-reabilitação psicossocial (valor atual de R\$412) voltado para assistência, acompanhamento e integração fora do ambiente hospitalar $^{4,5}$.

A regulamentação do PVC resultou da reinvindicação do movimento de Reforma Psiquiátrica Brasileira, elaborada durante a 2a Conferência Nacional de Saúde Mental que propôs a criação de mecanismos de repasse financeiro para pessoas que, após longo tempo de internação psiquiátrica, receberam alta, precisaram se reorganizar e encontrar seu lugar no espaço urbano. Nessa lógica, o PVC consiste em uma estratégia de desinstitucionalização que contribui para o desmonte do lugar direcionado para a 'loucura' ao transformar o sujeito-asilado em sujeito-autônomo $0^{6,7}$.

Para evitar cair no mero assistencialismo, espera-se que o referido programa seja empregado de modo a estimular a autonomia do sujeito, a qual é considerada, juntamente com a transformação cultural da sociedade, uma das bases para o processo de desinstitucionalização. Portanto, é necessário garantir o acesso aos benefícios aos quais os usuários têm direito e a execução de um projeto sustentável de vida que inclua a saída do claustro manicomial ${ }^{6,8}$.

No entanto, a concessão e a administração de benefícios monetários para usuários da rede de saúde mental é um dos nós que sustentam e amarram o trabalho nesse campo ${ }^{8}$, trazendo à tona dilemas que envolvem aspectos como o adoecimento, o acesso às políticas públicas e a garantia de direitos mínimos, reabilitação social, autonomia e contratualidade.

Até o presente momento não havia estudo que congregasse os resultados de diferentes pesquisas que abordassem o PVC e as suas repercussões nas práticas em saúde em diferentes realidades. É importante conhecer o estado da arte das publicações científicas sobre essa temática, de maneira a contribuir para a reflexão sobre o atual panorama da atenção psicossocial no Brasil, a qual tem sido alvo de tentativas de desmonte nos últimos anos. É relevante, ainda, avaliar as modificações em curso e apontar as transformações necessárias nesse contexto.

Como estratégia de desinstitucionalização no âmbito da Reforma Psiquiátrica Brasileira, e após 18 anos de regulamentação, os autores do presente estudo questionam: quais os aspectos abordados em produções científicas em relação ao PVC como estratégia de desinstitucionalização de egressos de internações psiquiátricas?

De modo a responder o questionamento proposto, achou-se oportuna a realização de uma revisão integrativa com o objetivo de identificar evidências científicas sobre os avanços, as possibilidades e os desafios do PVC para a desinstitucionalização de egressos de internações psiquiátricas.

\section{Métodos}

Trata-se de uma revisão integrativa da literatura, método que possibilita uma compreensão abrangente e a síntese do conhecimento produzido por diferentes estudos sobre um determinado fenômeno, incluindo estudos experimentais e não-experimentais. No campo da saúde, revisões integrativas trazem contribuições relevantes para a Prática Baseada em Evidências, considerandose que sua sistematização e ordenamento contribuem para o aprofundamento da compreensão sobre o tema investigado, podendo repercutir na prática em saúde?.

Desenvolveu-se a presente revisão integrativa da literatura conforme as seguintes etapas: elaboração da questão norteadora de forma clara e relevante para o campo da saúde; processo de busca dos artigos de acordo com os critérios e o processo de seleção; definição das informações a serem extraídas e coleta de dados; avaliação e 
análise crítica dos estudos considerando suas características, resultados e classificação de evidências; síntese, discussão e interpretação dos principais resultados; e apresentação da revisão integrativa, com a descrição detalhada de todas as etapas e com os principais achados ${ }^{10}$. Foram adotadas ainda as recomendações da diretriz Preferred Reporting Items for Systematic Reviews and Meta-Analyses - PRISMA, quanto à identificação, triagem, elegibilidade e inclusão de artigos na revisão ${ }^{10}$ que, apesar de indicada para revisões sistemáticas, foi utilizada na presente revisão a fim de orientar a seleção das referências e a apresentação das etapas de identificação, seleção, elegibilidade e inclusão dos estudos evidenciados na literatura.

Para definição da questão norteadora, foi utilizada a estratégia mnemônica representada pela sigla PVO, em que o "P” significa "Participantes" (egressos de internações psiquiátricas), o "V”, variável (Programa de Volta para Casa) e "O" significa Outcomes (Desinstitucionalização). Com a união destes componentes, chegou-se a seguinte pergunta norteadora: "Quais os aspectos abordados em produções científicas em relação ao PVC como estratégia de desinstitucionalização de egressos de internações psiquiátricas?”.

$\mathrm{O}$ processo de busca dos artigos se deu na Biblioteca Virtual em Saúde (BVS), no portal Pubmed, e nas bases de dados Scopus, Science Direct, Web of Science, CINAHL e PsycINFO; e envolveu os descritores "Política Pública, "Saúde Mental", "Desinstitucionalização", "Serviços Comunitários de Saúde Mental” e "Moradias assistidas" e seus respectivos equivalentes na língua inglesa, conforme catalogados pelos Descritores em Ciências da Saúde (DeCS) e pelo Medical Subject Headings (Mesh). Também foi selecionado o descritor controlado da American Psychological Association (APA): "Elaboração de Políticas Governamentais". Utilizou-se ainda a palavra-chave "Programa de Volta para Casa", de modo a conferir maior especificidade para a busca, de acordo com a questão norteadora.

A partir dos descritores e palavras-chave selecionados, foram elaborados três cruzamentos (A, B e C), utilizando-se os operadores booleanos "AND" e "OR": A - Desinstitucionalição AND Política Pública, B - Desinstitucionalização AND Saúde Mental e C - (Política Pública OR Saúde Mental OR Serviços Comunitários de Saúde Mental) AND (Desinstitucionalização OR Moradias Assistidas OR Programa de Volta para Casa).

A busca e seleção das produções científicas foram realizadas por dois pesquisadores separadamente, no mês de setembro de 2020, e as produções foram reunidas por meio do software Zotero. A análise de títulos e resumos foi feita de forma independente por dois pesquisadores com base em critérios de inclusão e exclusão. Os critérios de inclusão adotados foram: artigos científicos avaliados por pares, disponíveis na íntegra e em meio eletrônico, e que abordassem o PVC como estratégia de desinstitucionalização. Não foram estabelecidos critérios relacionados ao idioma de publicação do estudo e ao ano de publicação. Cartas, editoriais, dissertações e teses, além de produções que não ofereciam elementos para responder o questionamento proposto pela pesquisa e artigos duplicados, foram excluídos da amostra. A Figura 1 apresenta fluxograma com os resultados das etapas de identificação, seleção, elegibilidade e inclusão, conforme recomendado no PRISMA ${ }^{11}$.

Ao final, nove estudos foram incluídos na revisão integrativa. Os nove estudos foram encontrados na BVS, sendo que três deles também foram encontrados por meio da Web of Science e quatro deles na Scopus, porém, estas versões foram excluídas anteriormente, visto que caracterizavam duplicação dos estudos. Para a coleta de dados foi utilizado um protocolo, elaborado pelos autores dessa revisão integrativa, contendo as informações a serem extraídas dos artigos selecionados. As produções foram lidas, na íntegra, por dois pesquisadores que coletaram separadamente as seguintes informações: título, autoria, área de formação dos autores, mês/ano de submissão e mês/ano de publicação do estudo, periódico, idioma disponível, descritores/palavraschave, fonte de financiamento, delineamento metodológico, síntese dos resultados, recomendações dos autores e nível de evidência.

O nível de evidência dos artigos foi qualificado de acordo com o Agency for Healthcare and Research and Quality (AHRQ), o qual consiste em um dos instrumentos disponíveis para a classificação de estudos em diferentes níveis: (I) revisão sistemática ou metanálise; (II) ensaios clínicos randomizados; (III) ensaios clínicos sem randomização; (IV) estudos de coorte e de casocontrole; (V) revisão sistemática de estudos descritivos e qualitativos e (VI) único estudo descritivo ou qualitativo ${ }^{12}$.

Os resultados foram analisados de acordo com a estratégia de interpretação de práticas discursivas em materiais de domínio público, concebida como processo de produção de sentido ${ }^{13}$. A partir do processo de análise, foram definidos dois eixos de análise mediante a aproximação de sentidos produzidos: 'Modos de ser beneficiário na volta 


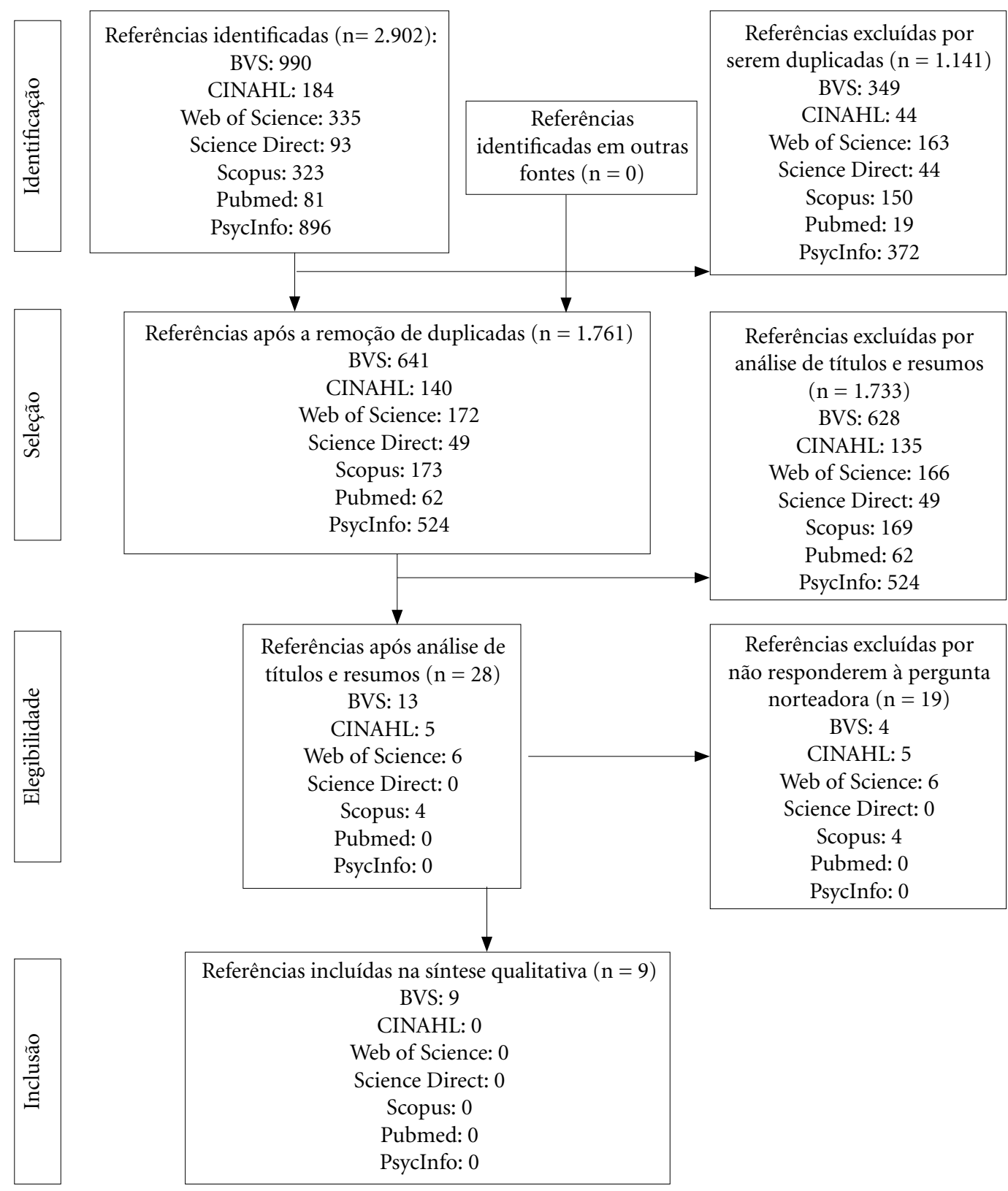

Figura 1. Fluxograma da seleção de referências nas bases de dados, adaptado com base no Preferred Reporting Items for Systematic Review and Meta-Analysis, Campo Grande, MS, Brasil, 2020.

Fonte: Autores.

para casa' e 'Avanços e desafios do Programa de Volta para Casa no processo de desinstitucionalização da vida. Produções de autores que abordavam os constructos teóricos políticas públicas de saúde mental e desinstitucionalização, foram utilizadas para fundamentar a discussão dos resultados.
A apresentação da síntese do conhecimento se deu por meio de texto descritivo sobre os estudos sumarizados e a apresentação de quadro com informações relevantes sobre os estudos analisados e que compuseram a revisão de literatura. 


\section{Resultados}

De acordo com o Quadro 1, as produções abordaram o PVC, não apenas sob o prisma do uso estrito do montante, mas de acordo com uma perspectiva ampla, associando-o a outras estratégias de desinstitucionalização, tais como: SRTs e Rede de Atenção Psicossocial (RAPS). Predominaram os autores com formação em Psicologia e os estudos disponíveis em língua portuguesa e publicados no periódico Saúde e Sociedade. Entre os 21 descritores utilizados para a identificação da temática abordada nos estudos, apenas 11 estavam catalogados no vocabulário DeCS. 'Saúde mental' foi utilizado como descritor em oito artigos e 'desinstitucionalização', em cinco.

Os artigos foram publicados a partir do ano de 2006; cinco deles, entre 2016 e 2019. Em mé-

Quadro 1. Distribuição dos artigos selecionados para a revisão integrativa segundo título do estudo, idioma disponível, área de atuação dos autores, periódico e descritores/palavras-chave. Campo Grande, MS, Brasil, 2020.

\begin{tabular}{|c|c|c|c|c|}
\hline Título do estudo & $\begin{array}{c}\text { Idioma } \\
\text { disponível }\end{array}$ & $\begin{array}{l}\text { Área de } \\
\text { atuação }\end{array}$ & Periódico & $\begin{array}{c}\text { Descritores/ } \\
\text { Palavras-chave }\end{array}$ \\
\hline $\begin{array}{l}\text { Artigo } 1 \text { - O Programa } \\
\text { de Volta para Casa na } \\
\text { vida cotidiana dos seus } \\
\text { beneficiários }^{14}\end{array}$ & $\begin{array}{l}\text { Português, } \\
\text { inglês }\end{array}$ & $\begin{array}{l}\text { Psicologia, } \\
\text { Medicina }\end{array}$ & $\begin{array}{l}\text { Saude } \\
\text { Soc }\end{array}$ & $\begin{array}{l}\text { Reforma Psiquiátrica; Saúde Mental; } \\
\text { Desinstitucionalização; Reabilitação } \\
\text { Psicossocial; Programa de Volta para } \\
\text { Casa }\end{array}$ \\
\hline $\begin{array}{l}\text { Artigo } 2 \text { - Construindo } \\
\text { histórias em tessitura lenta: } \\
\text { desinstitucionalização e } \\
\text { narrativas em pesquisa }^{15}\end{array}$ & Português & Psicologia & $\begin{array}{l}\text { Saude } \\
\text { Soc }\end{array}$ & $\begin{array}{l}\text { Narrativa; Saúde Mental; } \\
\text { Desinstitucionalização; Programa } \\
\text { de Volta para Casa; Avaliação de } \\
\text { Programas e Projetos de Saúde } \\
\end{array}$ \\
\hline $\begin{array}{l}\text { Artigo } 3 \text { - Narrativas e } \\
\text { sentidos do Programa de } \\
\text { Volta para Casa: voltamos, e } \\
\text { daí? }{ }^{16}\end{array}$ & Português & Psicologia & $\begin{array}{l}\text { Saude } \\
\text { Soc }\end{array}$ & $\begin{array}{l}\text { Desinstitucionalização; Saúde } \\
\text { Mental; Narração; Avaliação de } \\
\text { Programas e Projetos de Saúde; } \\
\text { Participação Cidadã em Ciência e } \\
\text { Tecnologia; Programa de Volta para } \\
\text { Casa }\end{array}$ \\
\hline $\begin{array}{l}\text { Artigo } 4 \text { - A concessão de } \\
\text { benefícios e a aposta na } \\
\text { singularidade: desafio para a } \\
\text { saúde mental }\end{array}$ & Português & Psicologia & $\begin{array}{l}\text { Rev } \\
\text { Latinoam. } \\
\text { Psicopat } \\
\text { Fundam }\end{array}$ & $\begin{array}{l}\text { Saúde Mental; Concessão de } \\
\text { benefícios; Psicanálise; Singularidade }\end{array}$ \\
\hline $\begin{array}{l}\text { Artigo } 5 \text { - Desvincular-se do } \\
\text { manicômio, apropriar-se da } \\
\text { vida: persistentes desafios da } \\
\text { desinstitucionalização }{ }^{17}\end{array}$ & Português & Psicologia & Psicol Soc & $\begin{array}{l}\text { Transtornos Mentais; Saúde Mental; } \\
\text { Desinstitucionalização Psiquiátrica; } \\
\text { Reforma Psiquiátrica; Reabilitação } \\
\text { Psicossocial }\end{array}$ \\
\hline $\begin{array}{l}\text { Artigo } 6 \text { - } \\
\text { Desinstitucionalização } \\
\text { psiquiátrica: do confinamento } \\
\text { ao habitar na cidade de Belo } \\
\text { Horizonte }^{18}\end{array}$ & Português & $\begin{array}{l}\text { Psicologia, } \\
\text { Teologia }\end{array}$ & Psicol Soc & $\begin{array}{l}\text { Serviço Residencial } \\
\text { Terapêutico; Subjetividade; } \\
\text { Desinstitucionalização; Programa de } \\
\text { Volta para Casa }\end{array}$ \\
\hline $\begin{array}{l}\text { Artigo } 7 \text { - Do Programa } \\
\text { de Volta para Casa à } \\
\text { conquista da autonomia: } \\
\text { percursos necessários } \\
\text { para o real processo de } \\
\text { desinstitucionalização } \\
\end{array}$ & Português & Psicologia & Physis & $\begin{array}{l}\text { Serviço Residencial } \\
\text { Terapêutico, Subjetividade, } \\
\text { Desinstitucionalização, Programa de } \\
\text { Volta para Casa }\end{array}$ \\
\hline $\begin{array}{l}\text { Artigo } 8 \text { - Gestão da atenção } \\
\text { à saúde mental no Sistema } \\
\text { Único de Saúde }\end{array}$ & $\begin{array}{l}\text { Português, } \\
\text { inglês }\end{array}$ & $\begin{array}{l}\text { Terapia } \\
\text { ocupacional, } \\
\text { Enfermagem }\end{array}$ & $\begin{array}{l}\text { Rev Esc } \\
\text { Enferm } \\
\text { USP }\end{array}$ & $\begin{array}{l}\text { Saúde Mental; Serviços de } \\
\text { Saúde; Política; Sistema Único de } \\
\text { Saúde }\end{array}$ \\
\hline $\begin{array}{l}\text { Artigo } 9 \text { - Avaliação da } \\
\text { situação atual dos Serviços } \\
\text { Residenciais Terapêuticos no } \\
\text { SUS }\end{array}$ & Português & Fisioterapia & $\begin{array}{l}\text { Cien } \\
\text { Saude } \\
\text { Colet }\end{array}$ & $\begin{array}{l}\text { Avaliação de Necessidades, Saúde } \\
\text { Mental, Reforma Psiquiátrica, } \\
\text { Avaliação de Programas e Serviços }\end{array}$ \\
\hline
\end{tabular}

Fonte: Autores. 
dia, 4,6 meses foram decorridos entre a submissão dos artigos aos periódicos e a publicação. Havia informação referente ao recebimento de financiamento para a realização do estudo em apenas uma pesquisa selecionada.

Segundo o Quadro 2, pesquisas com abordagem qualitativa, desenvolvidas especificamente com beneficiários do PVC, foram prevalentes. Do total de estudos selecionados, três eram multicêntricos; e três, foram realizados especificamente em Estados localizados no sudeste brasileiro. Conforme o AHRQ, todas as produções tinham nível de evidência VI. A síntese dos resultados dos estudos evidenciou os modos de ser benefici-

Quadro 2. Distribuição dos artigos selecionados para a revisão integrativa segundo delineamento e síntese dos resultados. Campo Grande, MS, Brasil, 2020.

\begin{tabular}{|c|c|c|}
\hline & Delineamento & Síntese dos resultados \\
\hline 葛 & $\begin{array}{l}\text { Pesquisa participativa; multiterritorial; } \\
\text { realizada com beneficiários, gestores, } \\
\text { profissionais e representantes de } \\
\text { movimentos sociais e do legislativo. Coleta } \\
\text { de dados através de entrevista e grupo focal }\end{array}$ & $\begin{array}{l}\text { O PVC viabiliza a desinstitucionalização, desospitalização, } \\
\text { reinserção social, autonomia, cidadania e contratualidade. } \\
\text { Incertezas governamentais, conflitos sociais, dificuldades } \\
\text { no acesso ao programa e desigualdades regionais na sua } \\
\text { distribuição desafiam sua efetivação. Recomenda-se a } \\
\text { ampliação da produção científica que avalia essa política em } \\
\text { âmbito nacional }\end{array}$ \\
\hline$\overbrace{\substack{\infty \\
\sum}}^{2}$ & $\begin{array}{l}\text { Pesquisa avaliativa, multicêntrica, realizada } \\
\text { com beneficiários. Coleta de dados através } \\
\text { de entrevista e produção de narrativas }\end{array}$ & $\begin{array}{l}\text { Existem desigualdades regionais na distribuição do benefício. } \\
\text { Apesar dos desafios no encontro entre beneficiários e } \\
\text { pesquisador, sugere-se a participação de ambos na produção } \\
\text { do saber sobre o tema }\end{array}$ \\
\hline 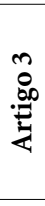 & $\begin{array}{l}\text { Pesquisa avaliativa, multiterritorial, } \\
\text { realizada com beneficiários. Dados } \\
\text { coletados através de observação } \\
\text { participante e entrevista. Análise de } \\
\text { narrativas }\end{array}$ & $\begin{array}{l}\text { O PVC promove desinstitucionalização, desospitalização, } \\
\text { utilização da RAPS, reinserção social, autonomia, } \\
\text { contratualidade e criticidade. Critica-se a não atualização } \\
\text { monetária do benefício ao longo dos anos }\end{array}$ \\
\hline 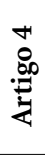 & $\begin{array}{l}\text { Estudo de casos de beneficiários no Rio de } \\
\text { Janeiro (RJ). Análise baseada na perspectiva } \\
\text { psicanalítica }\end{array}$ & $\begin{array}{l}\text { Benefícios viabilizam a reinserção social, mas podem } \\
\text { corroborar arranjos sintomáticos. Recomendam-se práticas } \\
\text { singulares e implicação do sujeito na concessão de benefícios, } \\
\text { além da reinserção social pelo trabalho }\end{array}$ \\
\hline 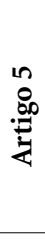 & $\begin{array}{l}\text { Pesquisa qualitativa, fundamentada no } \\
\text { paradigma construtivista, desenvolvida } \\
\text { no Rio de Janeiro (RJ), com beneficiários. } \\
\text { Coleta de dados em prontuários e através } \\
\text { de entrevista. Análise temática }\end{array}$ & $\begin{array}{l}\text { O benefício possibilita a vida na cidade e a ampliação } \\
\text { do poder de decisão e autonomia. Dependência dos } \\
\text { trabalhadores da saúde e apropriação insuficiente desse } \\
\text { recurso financeiro representam entraves para a reinserção } \\
\text { social. Recomenda-se a capacitação de trabalhadores da saúde } \\
\text { e o investimento na inserção social pelo trabalho }\end{array}$ \\
\hline$\stackrel{0}{\infty}$ & $\begin{array}{l}\text { Pesquisa-ação realizada em Belo Horizonte } \\
\text { (MG), com beneficiários. Coleta de dados } \\
\text { através de observação etnográfica e diário } \\
\text { de campo. Análise categorial }\end{array}$ & $\begin{array}{l}\text { O PVC tornou sustentável a política de desinstitucionalização. } \\
\text { Tal processo foi possível a partir da existência de uma rede de } \\
\text { assistência de saúde mental que acolhe e provê a continuidade } \\
\text { ao tratamento dos sujeitos e o resgate da cidadania }\end{array}$ \\
\hline$\stackrel{\substack{\infty \\
\infty}}{2}$ & $\begin{array}{l}\text { Estudo qualitativo realizado em Salvador } \\
\text { (BA), com beneficiários e profissionais } \\
\text { de saúde mental. Coleta de dados através } \\
\text { de observação participante, conversas } \\
\text { informais e diário de campo }\end{array}$ & $\begin{array}{l}\text { O PVC promove autonomia, empoderamento e autocuidado. } \\
\text { A literatura sobre o tema e suas repercussões é incipiente, } \\
\text { profissionais dão pouca importância ao programa e ao } \\
\text { seu potencial de desinstitucionalização; beneficiários } \\
\text { desconhecem, não se apropriam ou não têm autonomia no } \\
\text { uso do benefício }\end{array}$ \\
\hline$\stackrel{\infty}{\infty}$ & $\begin{array}{l}\text { Reflexão retrospectiva. Análise dos } \\
\text { mecanismos de gestão que repercutem na } \\
\text { Reforma Psiquiátrica }\end{array}$ & $\begin{array}{l}\text { O número de beneficiários do PVC ainda é baixo. Existe } \\
\text { grande dificuldade na desinstitucionalização da população } \\
\text { mais cronificada dos hospitais psiquiátricos }\end{array}$ \\
\hline$\stackrel{\substack{\infty \\
\infty}}{i}$ & $\begin{array}{l}\text { Dados de avaliação de SRTs e do PVC no } \\
\text { Brasil, obtidos de forma sistemática }\end{array}$ & $\begin{array}{l}\text { Existem desigualdades regionais no acesso ao PVC. O } \\
\text { número de beneficiários é baixo. Problemas na obtenção } \\
\text { de documentações e localização de familiares de referência } \\
\text { dificultam a desinstitucionalização }\end{array}$ \\
\hline
\end{tabular}


ário do PVC, os avanços e desafios do programa como estratégia de desinstitucionalização.

\section{Modos de ser beneficiário na volta para casa}

Os resultados de alguns dos estudos indicam que, embora a Reforma Psiquiátrica Brasileira proponha um processo de emancipação e o reconhecimento de direitos, não se pode perder de vista o sujeito a quem ela se destina. Historicamente, reservou-se à pessoa acometida por transtornos mentais, um lugar social onde ser humano era reduzido a uma massa anômala, ao lugar zero da troca, onde suas falas eram esvaziadas, incompreendidas e silenciadas. Os anos ininterruptos de internação em hospitais psiquiátricos depositaram nesse sujeito o estigma da loucura, do manicômio e da exclusão ${ }^{8,14,15,17}$.

Para alguns pesquisadores, apesar do surgimento de estratégias para retirar esse sujeito desse lugar social, a partir do movimento de Reforma Psiquiátrica, as marcas da longa experiência de vida no manicômio não desapareceram. Egressos de internações psiquiátricas lidam com as lembranças da experiência no contexto manicomial: as perdas, o abandono, as condições insalubres de vida, o desrespeito aos direitos humanos básicos, as cenas de violência e a alienação sofridas no confinamento. Experiências essas, que justificaram e contribuíram para o fechamento de hospitais psiquiátricos pelo país ${ }^{15,17}$.

Entre os achados de alguns estudos, destacase o fato de que ser beneficiário do PVC é ter um histórico de vida atravessada pela permanência em instituições fechadas. Essa permanência, por sua vez, provocou rupturas dos indivíduos consigo mesmos, com vínculos familiares e sociais, $\mathrm{e}$ com o mundo; e modificou a forma como esses sujeitos percebiam a si e seu entorno. A reclusão prolongada produziu negligência, vulnerabilidade socioeconômica, baixa escolaridade, dependência institucional e perda de condições laborais $^{16-18}$.

Entre as implicações dos muitos anos de internação, algumas produções sugerem a cronificação do transtorno mental com consequente perda de habilidades essenciais para a vida comunitária. Mesmo com a saída do manicômio, há registros de casos egressos de internações psiquiátricas com vivências cotidianas de estigmas e preconceitos, dificuldades de sobrevivência, formas precárias de moradia, dificuldades de inserção no mercado de trabalho, abandono familiar, readmissão em hospitais psiquiátricos, deterioração da qualidade de vida, adoecimento em virtu- de do envelhecimento e migração para moradia de rua e para o sistema prisional ${ }^{6,15,16}$.

Por outro lado, algumas produções científicas evidenciam as tentativas de desinstitucionalização desse sujeito através do acesso à moradia e renda mensal, reconstrução de vínculos familiares e outros vínculos afetivos, formas criativas de rede de apoio e circulação pelo território da cidade. Nesse sentido, ser beneficiário do PVC também significava ter a possibilidade de habitar a cidade, envolver-se no autocuidado e na organização da casa, e frequentar serviços da rede de saúde mental e centros de convivência ${ }^{6,14,15,17,18}$.

Resultados sugerem que apenas a minoria dos beneficiários possui uma rede que ultrapassa os contatos mantidos nos serviços de saúde mental. Uma pesquisa indicou a participação dos beneficiários em Centros de Atenção Psicossocial (CAPS) e ou centros de convivência, embora tais serviços nem sempre sejam reconhecidos como terapêuticos por esses sujeitos. As redes familiares ainda são restritas e mantidas esporadicamente ${ }^{17}$. Tais achados parecem reforçar as ideias de que, beneficiários do PVC têm dificuldades em expandir suas relações e possibilidades de vínculo, assim como em romper sua dependência com relação aos dispositivos assistenciais em saúde.

No tocante ao uso do benefício, parte da literatura selecionada evidencia que ser beneficiário não indica necessariamente ter autonomia para direcionar os gastos exclusivamente para atividades de interesse pessoal. Em decorrência de fatores como insuficiência de recursos transferidos pelas prefeituras para a manutenção de SRTs, vários estudos apontam que, parte das despesas com manutenção da casa e necessidades básicas (alimentação, vestuário, transporte e medicamentos não disponibilizados no Sistema Único de Saúde - SUS) é custeada com recursos do próprio beneficiário ${ }^{6,16-18}$.

\section{Avanços e desafios do Programa de Volta para Casa no processo de desinstitucionalização da vida}

Estudos sinalizam os avanços do PVC como estratégia de desinstitucionalização, à medida que possibilita mudanças na vida do beneficiário, com destaque para a ocupação concreta, por ele, de outro lugar na sociedade e a prescindibilidade do hospital psiquiátrico. As conquistas mais proeminentes, na perspectiva de alguns autores são: a saída do hospital, a permanência no meio comunitário, o exercício da cidadania, o acesso às políticas públicas, a circulação na cidade, a 
apropriação de suas casas, a aquisição de bens e serviços, o aumento da capacidade de expressão, de comunicação e de posicionamento crítico, a prática de autocuidado, o estabelecimento de relações afetivas, as novas esferas de contratualidade e negociação engendradas pelo dinheiro, além da salvaguarda de dignidade e direitos humanos $^{6,14-16}$.

Para alguns pesquisadores, ao prover um valor pecuniário mensal, o PVC abre espaço para que egressos de internação em instituições psiquiátricas deixem um lugar de assujeitamento e adentrem outro, o qual se destaca pela maior liberdade de ação e ressignificação da posição subjetiva, pelo direito à negociação e à inserção em um sistema de trocas sociais. Assim, podem ser citadas iniciativas como o financiamento de atividades e projetos de interesse pessoal do beneficiário, em alguns casos ${ }^{6,16-18}$.

Os achados de algumas produções denotam que o PVC contribui para a potencialização da autonomia do beneficiário, se comparado o nível de autonomia existente à época da internação ao atual. Esse fato pode ser exemplificado a partir da tomada de decisão, pelo sujeito, acerca de seu local de moradia, de sua escolha e de sua rotina nele; da manutenção de espaços privativos; e do modo de desfrutar a vida na cidade. Tais responsabilidades permitem, ao beneficiário, assumir o papel de sujeito de sua própria vida e sugerem a conquista da autonomia, a qual perpassa a legitimação do desejo do sujeito e a abertura de espaços onde possa se expressar ${ }^{16,17}$.

A maioria dos estudos selecionados ressalta que os níveis de autonomia entre beneficiários variam, inclusive no que diz respeito à administração do benefício. Há casos de gestão autônoma, de gestão compartilhada com terceiros e de gestão, exclusiva, de terceiros. Alguns achados denotam que o nível de autonomia de alguns beneficiários mostra-se muito restrito, o que traz implicações na apropriação do benefício, no conhecimento do recurso que passaram a dispor e nas limitações no ir e vir. Nesse ponto, reforça-se a autonomia como o estabelecimento de interdependência, que ocorre com maior ou menor negociação, além de depender de algumas variáveis, tais como: contexto local da rede, abertura da equipe profissional, organização familiar e limitações do beneficiário ${ }^{6,8,16,17,19}$.

Apesar das conquistas do PVC no campo da desinstitucionalização, desafios ainda se fazem presentes e demandam superação, sobretudo, no que diz respeito à integração social. Parte das produções denuncia que o PVC e outras estra- tégias de desinstitucionalização, não figuram, atualmente, entre as prioridades da agenda política no país, e reivindica o fortalecimento e o financiamento de ações inovadoras e a formação profissional voltada para a valorização e melhor atuação, na área da saúde mental ${ }^{6,14,15,17}$.

A despeito do aumento no número de beneficiários do PVC, observado nos últimos anos, o quantitativo continua aquém do potencial do programa. Pesquisadores estimam que, desde 2003, apenas um terço do total de 15 mil pessoas que poderiam ser contempladas no Brasil receba o benefício. Vários fatores contribuem para esse desfecho, entre eles a ausência de vínculos familiares ou curador, e a dificuldade de acesso a documentos civis, carteira de identidade, comprovante de endereço, conta bancária e comprovantes do histórico hospitalar (internações, tempo de permanência, passagem por diferentes hospitais $)^{6,7,19}$.

Desigualdades regionais no acesso ao PVC também estão entre os problemas identificados na literatura selecionada. Historicamente, os leitos de internação psiquiátrica concentravam-se nas regiões Sudeste e Nordeste do Brasil. Atualmente, ambas lideram a concentração de beneficiários e a implantação de serviços substitutivos aos manicômios. No entanto, a concentração dos números de beneficiários do PVC nessas duas regiões é desproporcional, se comparadas entre si, e ainda existe uma quantidade significativa de pessoas a serem desinstitucionalizadas em todo o território nacional ${ }^{14,19}$.

As críticas à falta de atualização monetária do benefício, ao longo dos anos, e ao desconhecimento de alguns beneficiários do recebimento desse recurso, são notórias em alguns estudos. Tais achados indicam redução no poder de contratualidade e negociação, o qual é mediado pelo dinheiro, com o decorrer do tempo, além de uma importante lacuna na implicação do sujeito na apropriação do benefício ${ }^{6,16,17}$.

Por fim, os resultados de alguns estudos apontam as dificuldades na articulação entre estratégias de desinstitucionalização (PVC e SRTs) com as de reabilitação psicossocial, tais como: trabalho, geração de renda e inserção social. Mesmo vivendo na comunidade, beneficiários do PVC ainda têm uma rede social restrita, parecem estar excluídos de um convívio social mais amplo, visto que se mantêm dependentes de trabalhadores da saúde mental, além de apresentarem vínculos familiares frágeis ou ausentes. Outro ponto que merece menção é a necessidade de desenvolvimento de estratégias de inserção social por meio 
do trabalho. Nesse sentido, projetos de trabalho assistido e oficinas de geração de renda poderiam aumentar as trocas de recursos e afetos ${ }^{6,8,17}$.

\section{Discussão}

Os autores dessa revisão integrativa tiveram dificuldades em localizar produções que abordassem o tema de interesse, mesmo sem utilizar critérios de inclusão que poderiam restringir o quantitativo de produções encontradas, como o idioma de publicação do estudo e o ano de publicação. Talvez, o uso de descritores não catalogados para a identificação do tema das produções seja um fator que dificulta a localização de outras pesquisas que também tenham abordado o assunto.

A quantidade de estudos selecionados revela o PVC como temática que merece maior interesse e atenção de órgãos de fomento e de pesquisadores. Novas produções científicas poderiam ser conduzidas por pesquisadores com formação em diferentes áreas de conhecimento, para além do campo da saúde, e desenvolvidas não apenas junto aos beneficiários mas, também, a outros atores sociais importantes no processo de desinstitucionalização.

A literatura científica selecionada e a pouca variedade dos desenhos metodológicos utilizados reforçam a necessidade de realização de novos estudos, incluindo aqueles de natureza experimental, o que poderia trazer resultados com maiores níveis de evidência. Considera-se oportuna também a realização de estudos sobre o PVC em diferentes cenários do território nacional, visto que o referido programa não se distribui uniformemente entre os diferentes estados e as regiões brasileiras.

Todos os estudos incluídos na presente revisão integrativa concebiam a desinstitucionalização não apenas como um movimento de desospitalização e redução de leitos psiquiátricos, mas como direcionamento de pessoas com transtornos mentais para serviços de saúde mental comunitários; mudança de um serviço único para um amplo leque de serviços e cuidados; e desconstrução dos saberes e práticas institucionalizados no tratamento da loucura. A prática da desinstitucionalização fundamenta-se no entendimento de que o hospital psiquiátrico não é o espaço adequado para o convívio de pessoas com transtornos mentais, fazendo-se necessária a construção de novos espaços de habitar e produzir subjetividade.

Em agosto de 1971, o então diretor do Hospital Psiquiátrico de Trieste, na Itália, o psiquiatra
Franco Basaglia, iniciou um projeto com vários segmentos sociais, que almejava desativar o referido hospital, devolver a liberdade aos doentes e possibilitar o resgate da dignidade e da cidadania perdidas com a internação. Para tanto, o tratamento hospitalar e manicomial foi substituído por novas estruturas assistenciais e terapêuticas em saúde mental no território, e agregado a mecanismos de apoio como cooperativas de trabalho protegido e moradias assistidas. Iniciava-se na Itália uma luta política para transformar, socialmente, o modo de lidar com a loucura que traria expressivas repercussões no mundo ${ }^{20}$.

Nos Estados Unidos, a desinstitucionalização surgiu como um conjunto de medidas de desospitalização que incluía a prevenção de internações psiquiátricas, a possibilidade de realização de tratamento na comunidade, e o estabelecimento e a manutenção de sistemas de suporte comunitário para pessoas não-institucionalizadas. Basaglia ampliou e consolidou um novo significado para o conceito em questão, o qual foi marcado pela crítica epistemológica ao saber médico psiquiátrico e pelo questionamento dos limites que a doença mental impunha aos direitos do cidadão ${ }^{21}$.

Os movimentos de Reforma Psiquiátrica italiana e brasileira transcorreram em distintos contextos históricos e culturais. Apesar da Política Nacional de Saúde Mental no Brasil não ter conseguido extinguir todos os leitos psiquiátricos, como ocorreu na Itália, foi bem sucedida na redução dos mesmos e na consolidação de uma rede de serviços de saúde mental que, com dificuldades, direciona a assistência psiquiátrica ${ }^{22}$.

Os modos de ser do egresso de longas internações psiquiátricas e beneficiário do PVC, evidenciados nessa revisão integrativa, coadunam com a máxima de que o processo de desinstitucionalização torna possível a construção e a invenção de novas perspectivas de vida e de subjetividade, não reduzindo tais transformações apenas a 'evoluções' e 'prognósticos' de uma doença mental ${ }^{21}$.

A internação psiquiátrica aloca o sujeito em um lugar de subtração de trocas e de manutenção de relações de dependência pessoal. No âmbito da desinstitucionalização e da atenção territorial, as ações que mais transformam relações e reordenam posições são aquelas que menos infantilizam e incapacitam o sujeito com transtorno mental e que mais elevam o saber social e estimulam o empoderamento, uma vez que fortalecem a inserção, a contratualidade social, a expressão e a simetria nas relações ${ }^{23,24}$.

Nesse ponto, a autonomia - constructo abordado em algumas das produções selecionadas - 
emerge como conceito-chave para pensar os objetivos da Reforma Psiquiátrica e refletir sobre o PVC como estratégia de desinstitucionalização. A produção de autonomia do sujeito excluído, ou em desvantagem social, inclui a produção de vida em articulação com redes de suporte formais e informais, espaços de convivência, trabalho, lazer, cultura e arte, assim como o acesso a direitos de cidadania e políticas públicas ${ }^{25}$.

Independentemente do nível de autonomia do beneficiário, reitera-se a necessidade de que estudos sobre o PVC investiguem os diferentes tipos de apoio ofertados ao sujeito na tomada de decisões, na apropriação do recurso financeiro e na compreensão dos significados e do valor do dinheiro na sociedade atual. Na lógica da desinstitucionalização, esses elementos podem contribuir para uma maior compreensão do processo de produção de autonomia no sujeito.

Apesar das contribuições do PVC no tocante à desinstitucionalização evidenciadas na literatura, movimentos de Reforma Psiquiátrica em todo o mundo enfrentaram, e ainda enfrentam, desafios relativos à ruptura com conceitos e práticas do modelo psiquiátrico e à invenção de um novo paradigma científico, ético e político. Pela natureza própria de produzir tensões de ordens diversas, tais reformas sofrem rejeições, ataques sociais, culturais e políticos. Até o presente momento, nenhum desses movimentos revelou-se como uma conquista histórica definitiva ${ }^{26,27}$.

Anteriormente à experiência de Triste, por exemplo, Basaglia liderou duas tentativas de superação do modelo manicomial nos Hospitais Psiquiátricos de Gorizia e Colorno sem o êxito esperado. Entre os entraves para alcançar o objetivo, estavam a resistência da administração local em viabilizar a proposta de desinstitucionalização e assistência psiquiátrica no território, as dificuldades de ordem administrativa e a falta de apoio político ${ }^{20}$.

Para ilustrar a transformação da realidade brasileira, entre 2002 e 2015 foram fechados progressivamente mais de $58 \%$ dos leitos do SUS em hospitais psiquiátricos com características asilares, ao passo que foi implementada uma rede de serviços substitutivos e estabelecida a RAPS com forte base territorial. Até 2015 foram implementados 2.209 CAPS, criadas 619 SRTs e mais de 4 mil pessoas foram beneficiadas pelo $\mathrm{PVC}^{28}$.

Atualmente, a crise brasileira nos campos social, político, econômico e sanitário; atrelada à gestão de grupos políticos autoritários, de ideário liberal e que desprezam políticas sociais, tem provocado repetidos retrocessos no âmbito da saúde mental na forma de desmonte da RAPS. As novas diretrizes para a política de saúde mental, por exemplo, introduziram hospitais psiquiátricos e comunidades terapêuticas na RAPS e criaram linhas de financiamento de serviços psiquiátricos privados $^{26,29}$.

Além disso, ainda existem municípios que não aderiram nem implantaram políticas e estratégias que viabilizassem a desinstitucionalização, como o PVC e os SRTs. Somado a esse cenário, o Estado também não tem oferecido recursos e incentivos necessários para componentes importantes da rede de atenção à saúde mental, como centros de convivência e cooperativas, os quais podem contribuir para o desenvolvimento da autonomia e da reinserção social do sujeito ${ }^{30}$.

Em síntese, o panorama evidenciado na presente revisão integrativa indica que o modo de ser beneficiário do PVC é, ao mesmo tempo, ter para si a chance de protagonizar a própria vida e história. Chance essa que é perpassada por danos históricos à sua saúde mental e por arranhaduras na possibilidade de ser um ente social autônomo. Essas barreiras podem ser percebidas nas dificuldades vivenciadas diariamente por esse sujeito. Esses percalços passam a desafiar o beneficiário em seu microespaço de atuação, em suas tarefas diárias, em suas tentativas de pertencimento aos lugares e em suas relações com os outros. Para além disso, o perfil do egresso do claustro manicomial e atual beneficiário do PVC configura, por si só, um desafio para a própria estratégia assistencial, em sua busca por promover desinstitucionalização e inserção social.

Ao mesmo tempo, entende-se que a ideia do PVC, no contexto de desinstitucionalização psiquiátrica e da promoção de saúde mental, não passa pela atuação como fator de desresponsabilização do poder público ou por empurrar o sujeito para sua autonomia plena, fato que não condiz com suas possibilidades para tal. O PVC deve atuar como potencializador da participação em sociedade, conforme o modo como o indivíduo pode relacionar-se e exercer seu papel nela. É preciso, para tanto, fomentar condições políticas adequadas.

\section{Considerações finais}

Apesar do baixo nível das evidências encontradas nos estudos, tem-se que o PVC trouxe avanços no campo das conquistas sociais e da desinstitucionalização de egressos de internações psiquiátricas. No entanto, o programa enfrenta desafios 
que precisam ser superados no tocante ao acesso, distribuição equitativa nas diferentes regiões do Brasil, capacitação profissional para melhor atuação e utilização do programa, e implicação do sujeito na apropriação do benefício.

Recomenda-se o financiamento e o desenvolvimento de pesquisas científicas, com diferentes desenhos metodológicos e maiores níveis de evidência, que abordem o PVC enquanto estratégia de desinstitucionalização em âmbitos local e nacional. É relevante que esses estudos incluam diferentes atores com a finalidade de identificar avanços e entraves na concretização e fortalecimento do programa. Também é primordial que as investigações articulem o PVC com outras estratégias de produção de autonomia, resgate da cidadania, acesso a rede de saúde mental, retorno ao convívio familiar e inserção do beneficiário no mercado de trabalho.

\section{Colaboradores}

Todos os autores tiveram igual participação na concepção e delineamento do estudo, análise e interpretação dos dados, redação e revisão crítica do artigo. 


\section{Referências}

1. Foucault M. A arqueologia do saber. $5^{\mathrm{a}}$ ed. Rio de Janeiro: Forense Universitária; 1997.

2. Amarante P, Nunes MO. A reforma psiquiátrica no SUS e a luta por uma sociedade sem manicômios. Cien Saude Colet 2018; 23(6):2067-2074.

3. Rotelli F, Leonardis O, Mauri D. Desinstitucionalização: uma outra via. In: Nicácio MFS, organizadora. Desinstitucionalização. 2a ed. São Paulo: Hucitec; 2001.

4. Brasil. Lei $n^{\circ} 10.708$ de 31 de julho de 2003. Institui o auxílio-reabilitação psicossocial para pacientes acometidos de transtornos mentais egressos de internações. Diário Oficial da União; 31 jul.

5. Brasil. Lei no 1.511 de 24 de julho de 2013. Reajusta o valor do benefício para R\$412,00. Diário Oficial da União; 24 jul.

6. Lima SS, Brasil SA. Do Programa de Volta para Casa à conquista da autonomia: percursos necessários para o real processo de desinstitucionalização. Physis 2014; 24(1):67-88.

7. Barros $\mathrm{S}$, Salles M. Gestão da atenção à saúde mental no Sistema Único de Saúde. Rev Esc Enferm USP 2011; 45(1):1780-1785.

8. Hasky F, Frare AP. A concessão de benefícios e a aposta na singularidade: um desafio para a saúde mental. Rev Latinoam Psicopat Fundam 2016; 19(1):99-113.

9. Esswein GC, Rovaris AF, Rocha GP, Levandowski DC. Ações em saúde mental infantil no contexto da Atenção Básica do Sistema único de Saúde (SUS): uma revisão integrativa da literatura brasileira. Cien Saude Colet 2021; 26(2):3765-3780.

10. Mendes KDS, Silveira RCCP, Galvão CM. Revisão integrativa: método de pesquisa para a incorporação de evidências na saúde e na enfermagem. Texto Contexto Enferm 2008; 17(4):758-764.

11. Moher D, Liberati A, Tetzlaff J, Altman DG. Preferred reporting items for systematic reviews and meta-analyses: the PRISMA statement. PLoS Med 2009; 6(7):1-7.

12. Souza MT, Silva MD, Carvalho R. Revisão integrativa: o que é e como fazer. Einstein 2010; 8(1):102-106.

13. Spink MJ, organizadora. Práticas discursivas e produção de sentidos no cotidiano. Rio de Janeiro: Centro Edelstein de Pesquisas Sociais; 2013.

14. Guerrero AVP, Bessoni EA, Cardoso AJC, Vaz BC, Braga-Campos FC, Badaró MIM. O Programa de Volta para Casa na vida cotidiana dos seus beneficiários. Saude Soc 2019; 28(3):11-20.

15. Koosah J, Moreira MIB, Braga-Campos FC. Construindo histórias em tessitura lenta: desinstitucionalização e narrativas em pesquisa. Saude Soc 2019; 28(3):29-39.

16. Bessoni E, Capistrano A, Silva G, Koosah J, Cruz K, Lucena M. Narrativas e sentidos do Programa de Volta para Casa: voltamos, e daí? Saude Soc 2019; 28(3):4053.
17. Salles ACRR, Miranda L. Desvincular-se do manicômio, apropriar-se da vida: persistentes desafios da desinstitucionalização. Psicol Soc 2016; 28(2):369-379.

18. Franco RF, Stralen CJV. Desinstitucionalização psiquiátrica: do confinamento ao habitar na cidade de Belo Horizonte. Psicol Soc 2015; 27(2):312-321.

19. Furtado JP. Avaliação da situação atual dos Serviços Residenciais Terapêuticos no SUS. Cien Saude Colet 2006; 11(3):785-795.

20. Basaglia F. Escritos selecionados em saúde mental e reforma psiquiátrica. Rio de Janeiro: Garamond; 2005.

21. Amarante P. O homem e a serpente: outras histórias para loucura e psiquiatria. Rio de Janeiro: Fiocruz; 1996.

22. Kantorski LP, Cardano M, Antonacci MH, Guedes AC. Política de saúde mental brasileira: uma análise a partir do pensamento de Franco Basaglia. J Nurs Health 2021; 11(2):1-19.

23. Basaglia F. A instituição negada. Rio de Janeiro: Graal; 1991.

24. Rotelli F, De Leonardis O, Mauri D. Desinstitucionalização. São Paulo: Hucitec; 1990.

25. Amarante P, Torre EHG. "De volta à cidade, sr. cidadão!” - reforma psiquiátrica e participação social: do isolamento institucional ao movimento antimanicomial. Rev Adm Publica 2018; 52(6):1090-1107.

26. Nunes MO, Lima Júnior JM, Portugal CM; Torrente M. Reforma e contrarreforma psiquiátrica: análise de uma crise sociopolítica e sanitária a nível nacional e regional. Cien Saude Colet 2019; 24(12):4489-4498.

27. Yasui S. Rupturas e encontros: desafios da reforma psiquiátrica brasileira. Rio de Janeiro: Fiocruz; 2010.

28. Braga C. Argumentos para utopias da realidade e a experiência da reforma psiquiátrica brasileira. Saude Soc 2020; 29(3):1-11.

29. Brasil. Ministério da Justiça (MJ). Resolução no 1 de 9 de março de 2018. Define as diretrizes para o realinhamento e fortalecimento da PNAD - Política Nacional sobre Drogas, aprovada pelo Decreto 4.345, de 26 de agosto de 2002. Diário Oficial da União 2018; 9 mar.

30. Martinhago F, Oliveira WF. (Des)institucionalização: a percepção dos profissionais dos Centros de Atenção Psicossocial de Santa Catarina, Brasil. Saude Soc 2015; 24(4):1273-1284.

Artigo apresentado em 31/10/2020

Aprovado em 16/10/2021

Versão final apresentada em 18/10/2021

Editores-chefes: Romeu Gomes, Antônio Augusto Moura da Silva 